Supporting Information for

\title{
Electron beam patterning of metal-organic frameworks
}

$$
\text { Yurun Miao }{ }^{1} \text { and Michael Tsapatsis } 1,2,3 *
$$

1. Johns Hopkins University, Institute for NanoBioTechnology, 3400 North Charles St, Baltimore, MD 21218 USA

2. Johns Hopkins University, Department of Chemical and Biomolecular Engineering, 3400 North Charles St, Baltimore, MD 21218 USA

3. Applied Physics Laboratory, Johns Hopkins University, 11100 Johns Hopkins Road, Laurel, MD 20723 USA 


\section{Supporting Figures:}

a

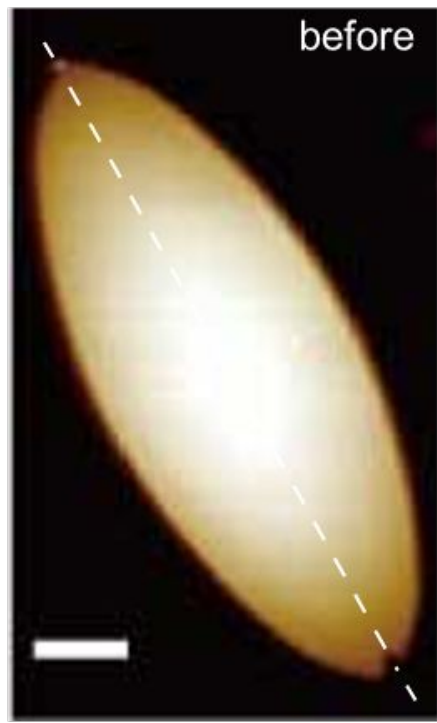

b

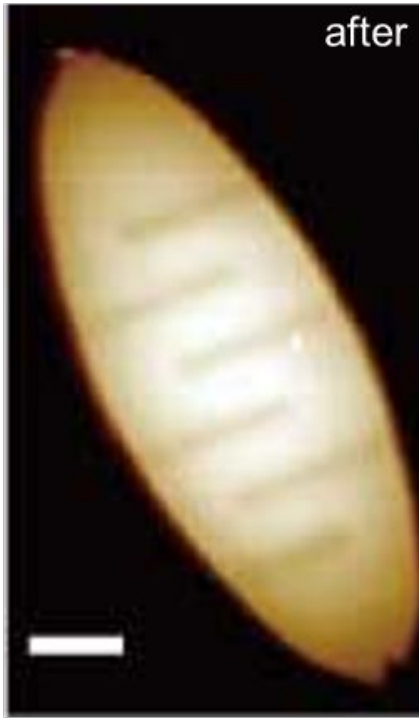

$300 \mathrm{~nm}$

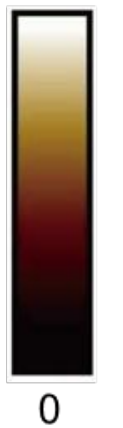

C

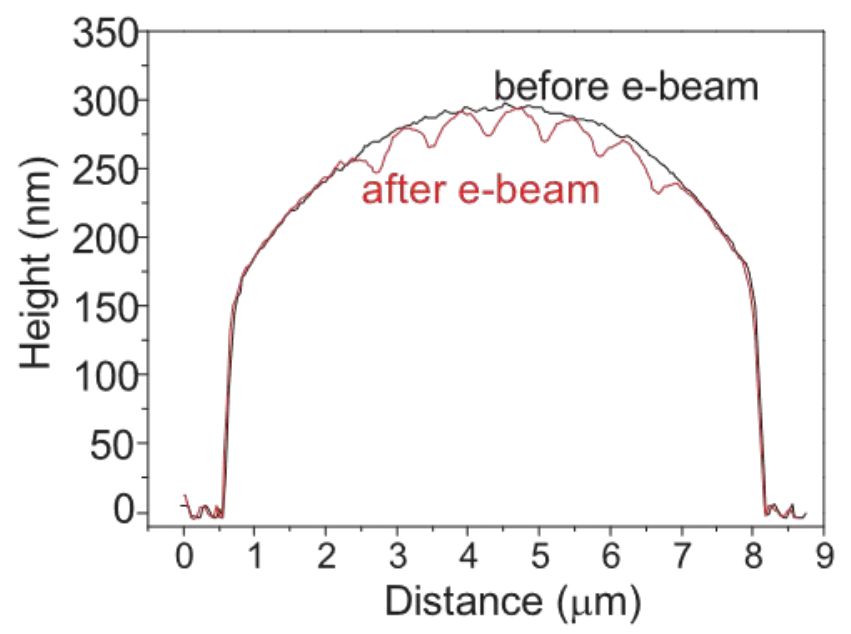

Figure S1. AFM images of a ZIF-L particle before (a) and after (b) e-beam exposure with a staggered stripe pattern at $5 \mathrm{kV}$ acceleration voltage and $10 \mathrm{mC} / \mathrm{cm}^{2}$ electron dose, and corresponding height profiles (c) measured across the long dimension of the particle (shown by the dashed line in a). Scale bars are $1 \mu \mathrm{m}$. 

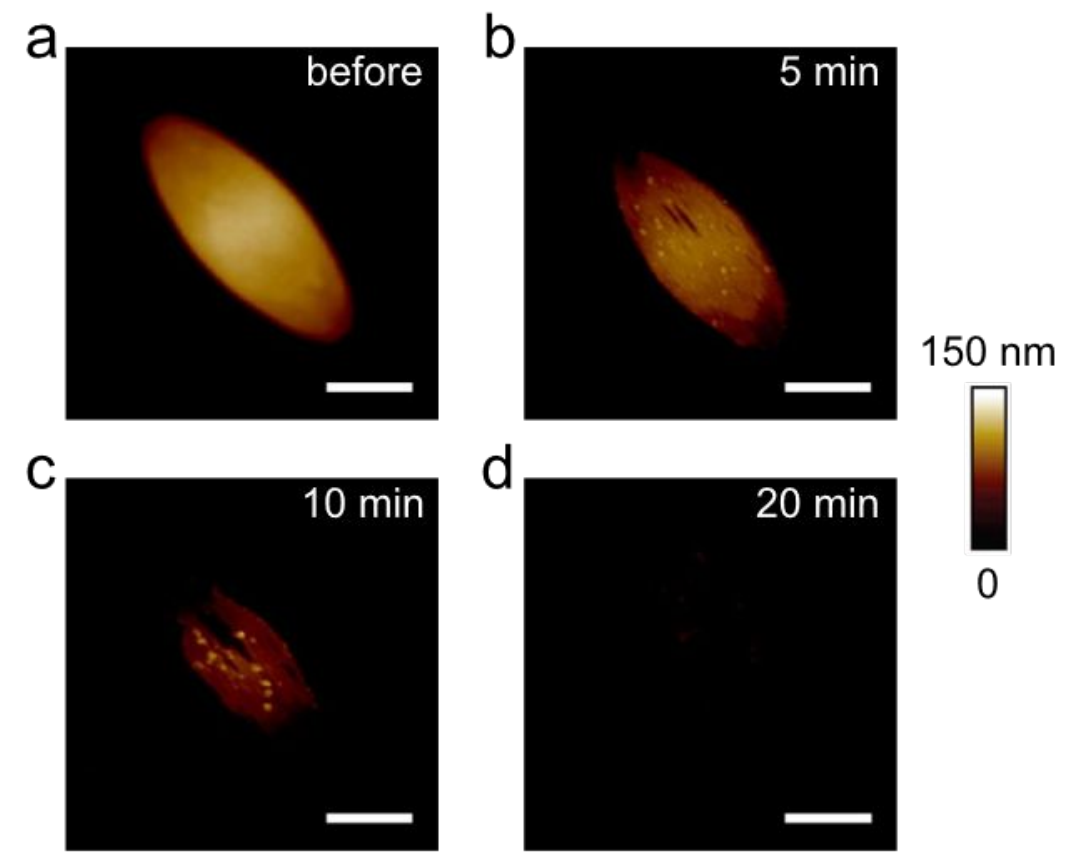

Figure S2. AFM images of a non-irradiated ZIF-L particle before (a) and after dissolution in water for 5 (b), 10 (c) and 20 (d) min. Scale bars are $1 \mu \mathrm{m}$. 
a
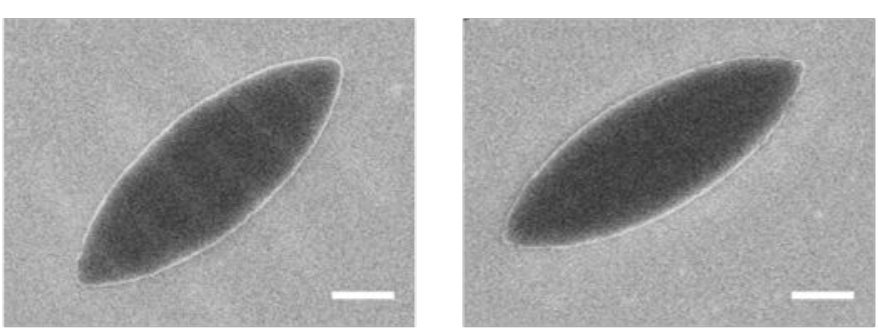

b
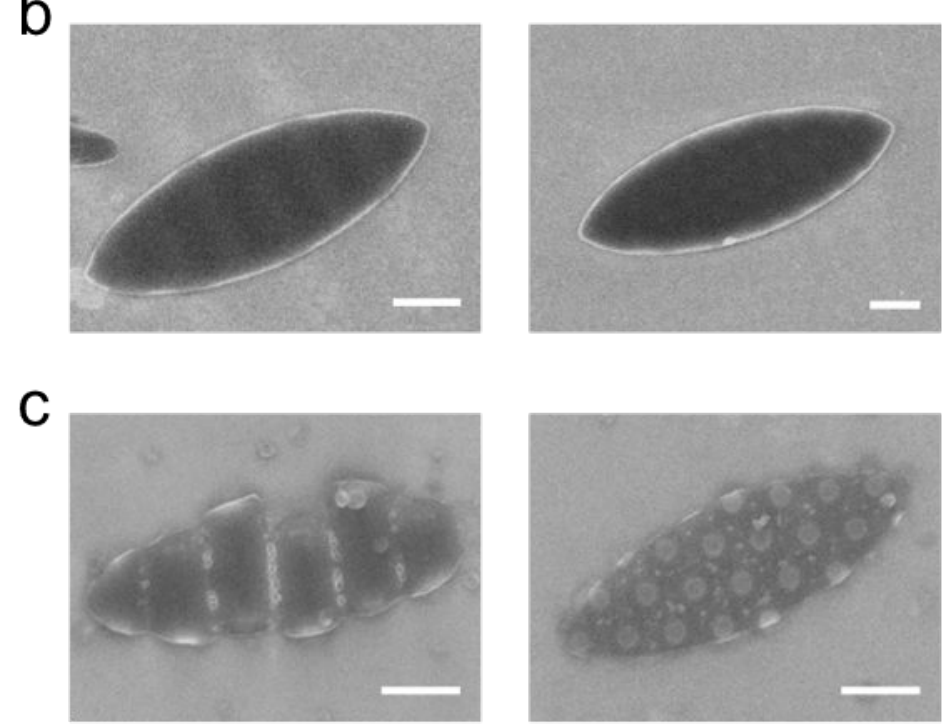

Figure S3. SEM images of e-beam patterned ZIF-L particles after dissolution in different solvents. Particles are first irradiated with stripe or dot pattern at $5 \mathrm{kV}$ with $10 \mathrm{mC} / \mathrm{cm}^{2}$ dose, followed by dissolution in acetonitrile (a), N,N-dimethylformamide (b) and methanol (c) for 24 h. Scale bars are $1 \mu \mathrm{m}$. 

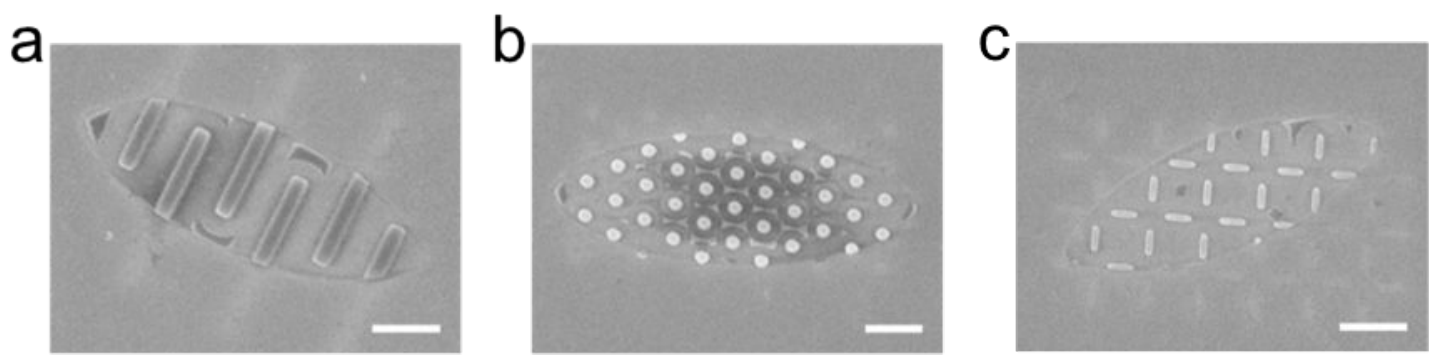

Figure S4. SEM images of e-beam patterned ZIF-L particles after dissolution in pyridine for $24 \mathrm{~h}$. Particles are first irradiated at $5 \mathrm{kV}$ with $10 \mathrm{mC} / \mathrm{cm}^{2}$ dose, followed by dissolution in pyridine for $24 \mathrm{~h}$. Scale bars are $1 \mu \mathrm{m}$. 

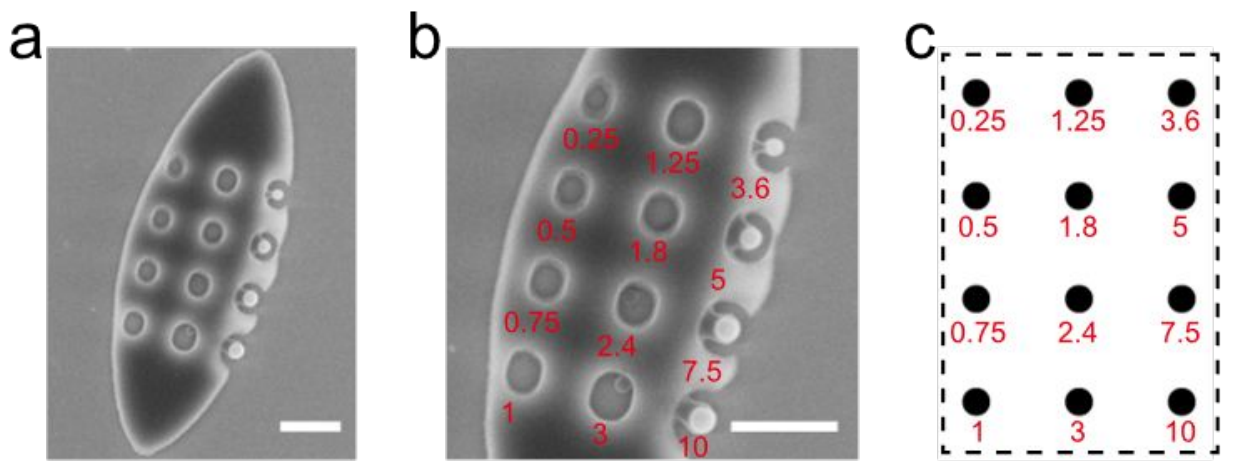

Figure S5. SEM image (a) and enlarged view (b) of a ZIF-L particle irradiated with a dot array (c) of different electron doses followed by dissolution in pyridine for $24 \mathrm{~h}$. The ZIF-L particle is irradiated at $5 \mathrm{kV}$ and electron dose in $\mathrm{mC} / \mathrm{cm}^{2}$ is labeled below each dot in (b) and (c). Scale bars are $1 \mu \mathrm{m}$. 

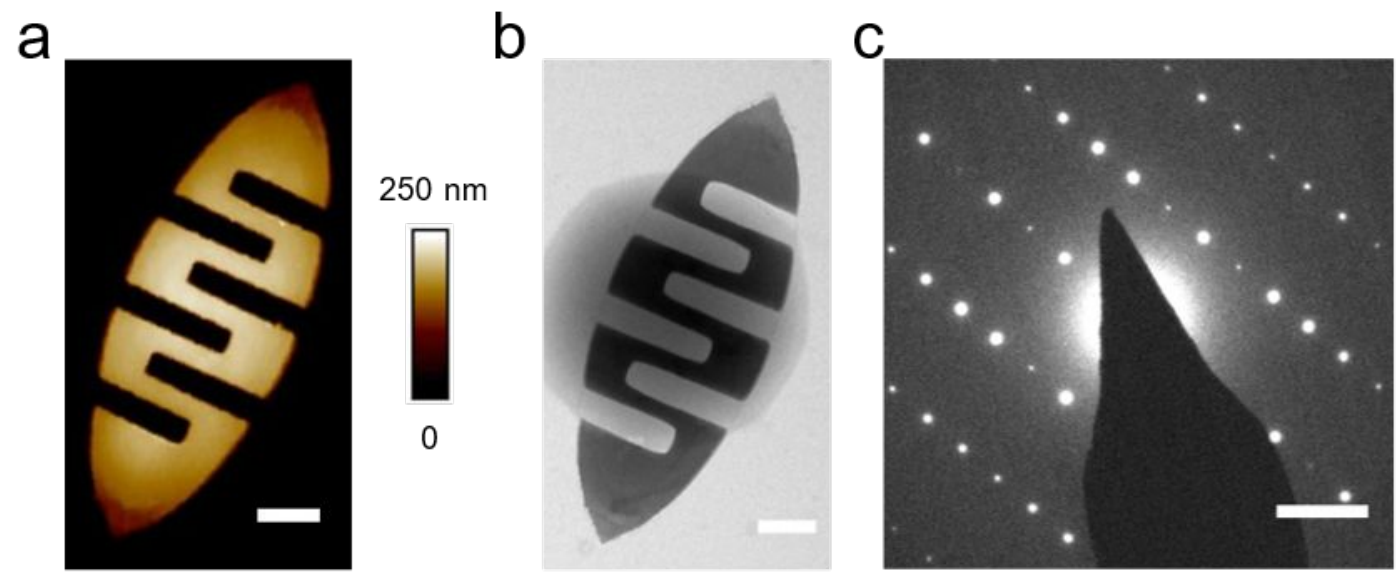

Figure S6. AFM (a), TEM image (b) and electron diffraction pattern (c) of a ZIF-L particle irradiated with a stripe pattern followed by dissolution in pyridine for $24 \mathrm{~h}$ (electron dose: 1 $\mathrm{mC} / \mathrm{cm}^{2}$; acceleration voltage $5 \mathrm{kV}$ ). Scales bars are $1 \mu \mathrm{m}$ in a and $\mathrm{b}$, and $1 \mathrm{~nm}^{-1}$ in $\mathrm{c}$. 

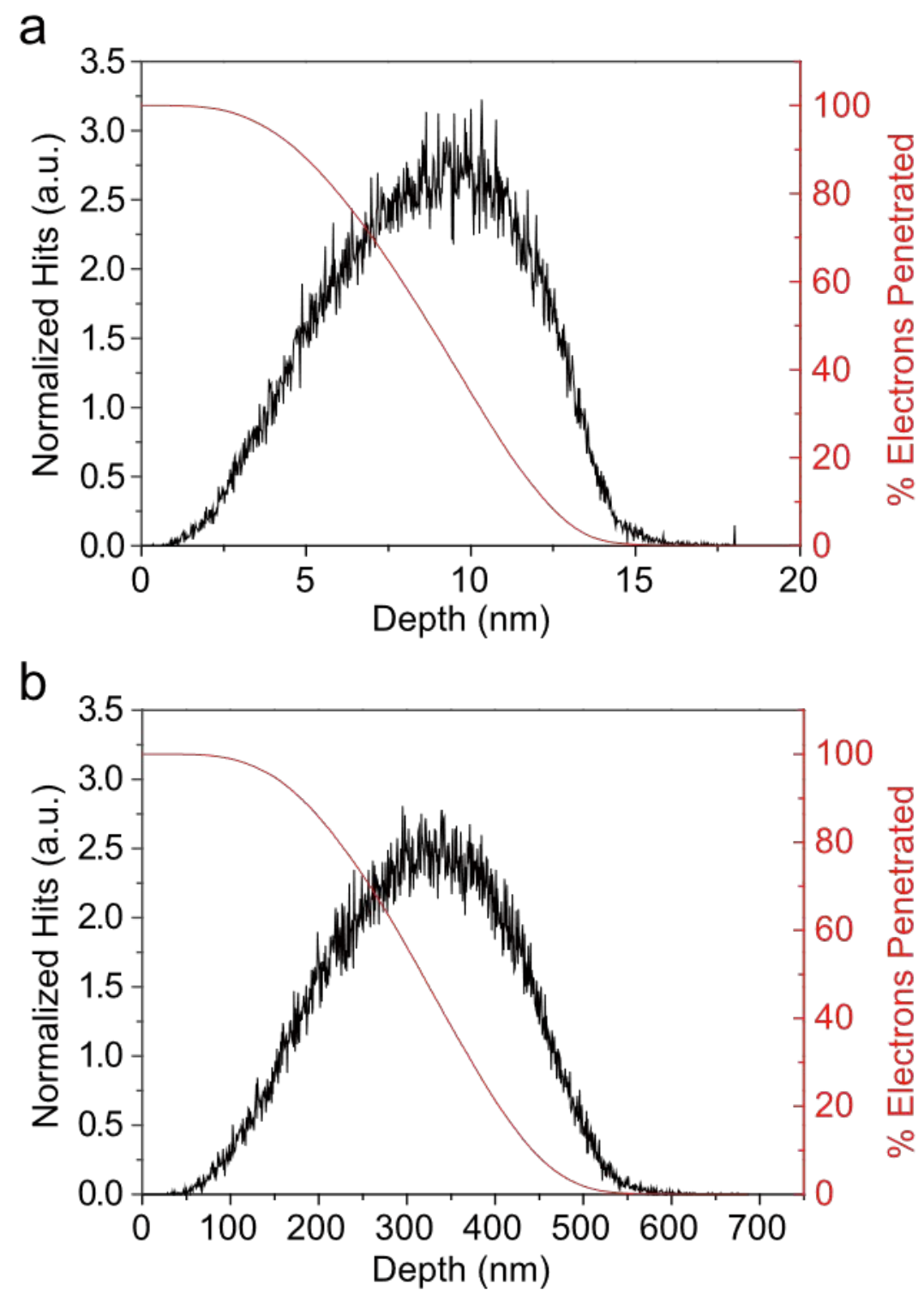

Figure S7. Monte Carlo simulations of maximum penetration depth of electrons and percentage of penetration in ZIF-L at $500 \mathrm{eV}$ (a) and $5 \mathrm{keV}$ (b) using the CASINO modeling tool. ${ }^{1}$ 
a

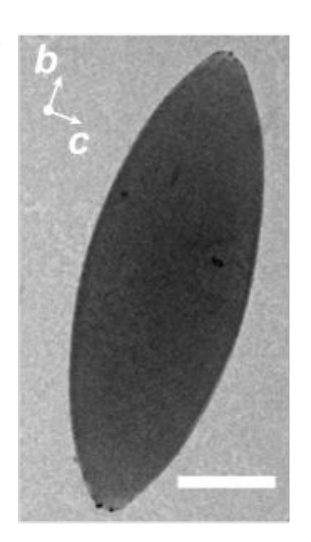

b

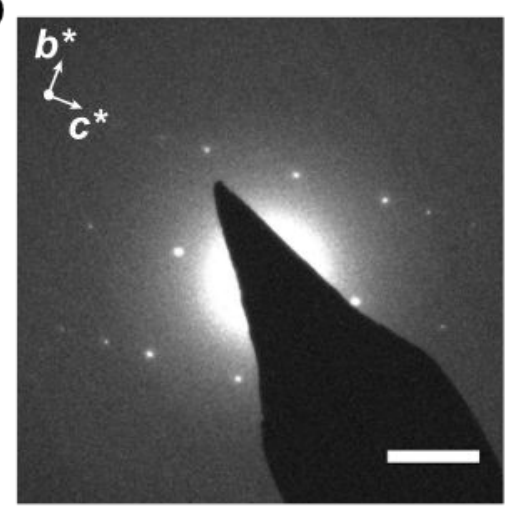

Figure S8. TEM image (a) and the corresponding electron diffraction pattern (b) of a ZIF-L particle previously exposed to e-beam at $350 \mathrm{eV}$ and $10 \mathrm{mC} / \mathrm{cm}^{2}$ dose. Scale bar is $1 \mu \mathrm{m}$ in (a) and $1 \mathrm{~nm}^{-1}$ in (b). 

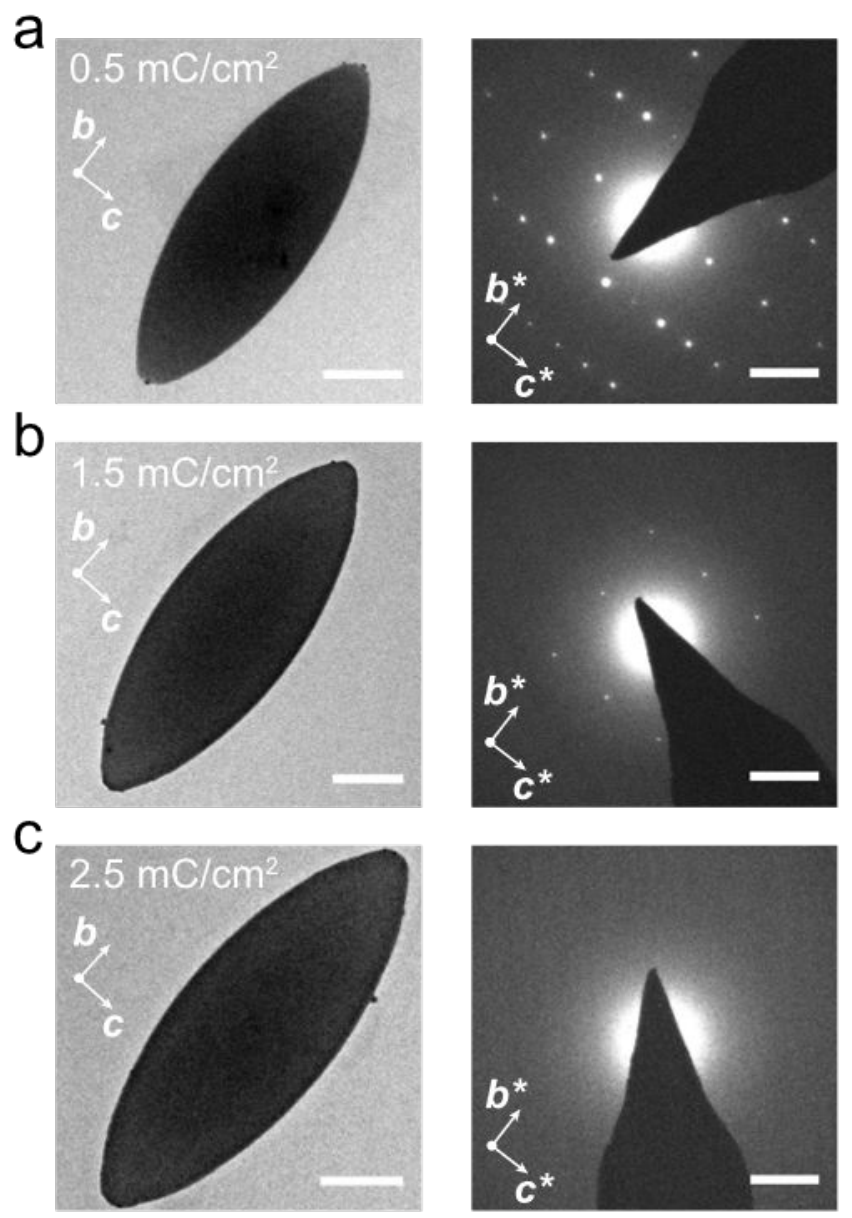

Figure S9. TEM images and the corresponding electron diffraction (ED) patterns of ZIF-L particles previously exposed to e-beam at $5 \mathrm{keV}$ with a dose of 0.5 (a), 1.5 (b) or 2.5 (c) $\mathrm{mC} / \mathrm{cm}^{2}$. Scale bars are $1 \mu \mathrm{m}$ for TEM images and $1 \mathrm{~nm}^{-1}$ for ED patterns. 

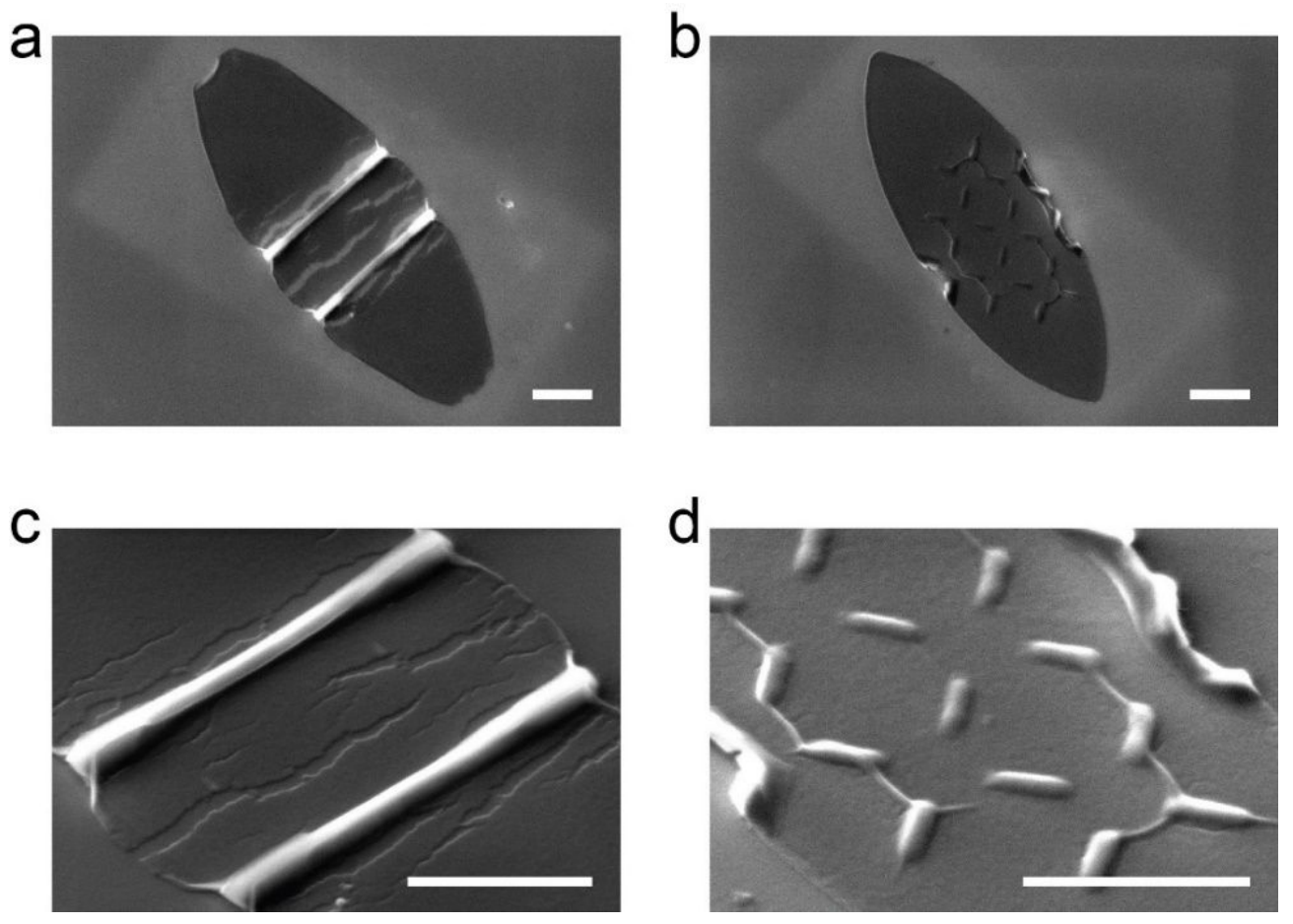

Figure S10. SEM images of ZIF-L particles prepared by combined e-beam irradiation at low and high energy with non-enclosing patterns. Particles are irradiated first over the entire particle at $500 \mathrm{eV}$, then with patterns of lines (a) and grids (b) at $5 \mathrm{keV}$ (both with a dose of $10 \mathrm{mC} / \mathrm{cm}^{2}$ ), followed by dissolution in water for $4 \mathrm{~h} .45^{\circ}$ tilted views in $\mathrm{c}$ and $\mathrm{d}$ correspond to $\mathrm{a}$ and $\mathrm{b}$, respectively. Scale bars are $1 \mu \mathrm{m}$. 


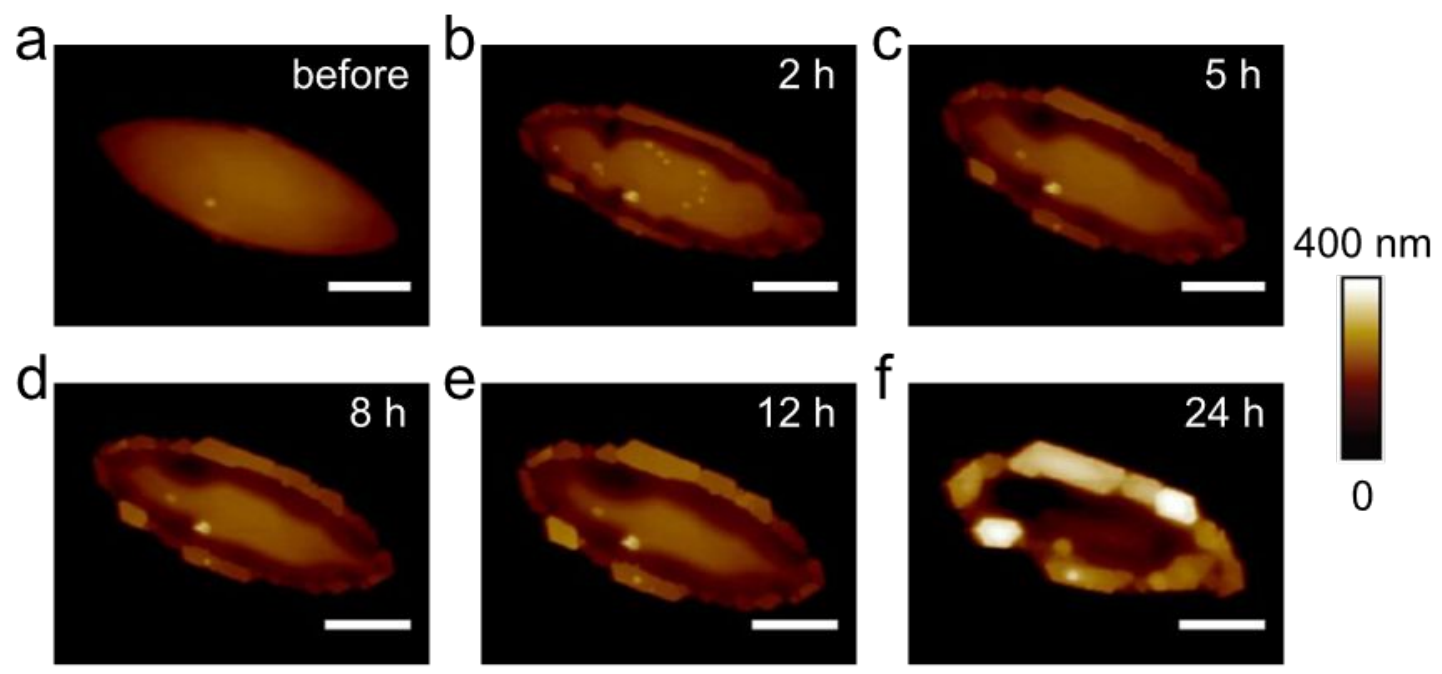

Figure S11. AFM images of a non-irradiated ZIF-L particle before (a) and after VPLT with 2$\mathrm{mIm}$ at $100{ }^{\circ} \mathrm{C}$ for 2 (b), 5 (c), 8 (d), 12 (e), 24 (f) hours. Scale bars are $1 \mu \mathrm{m}$. 

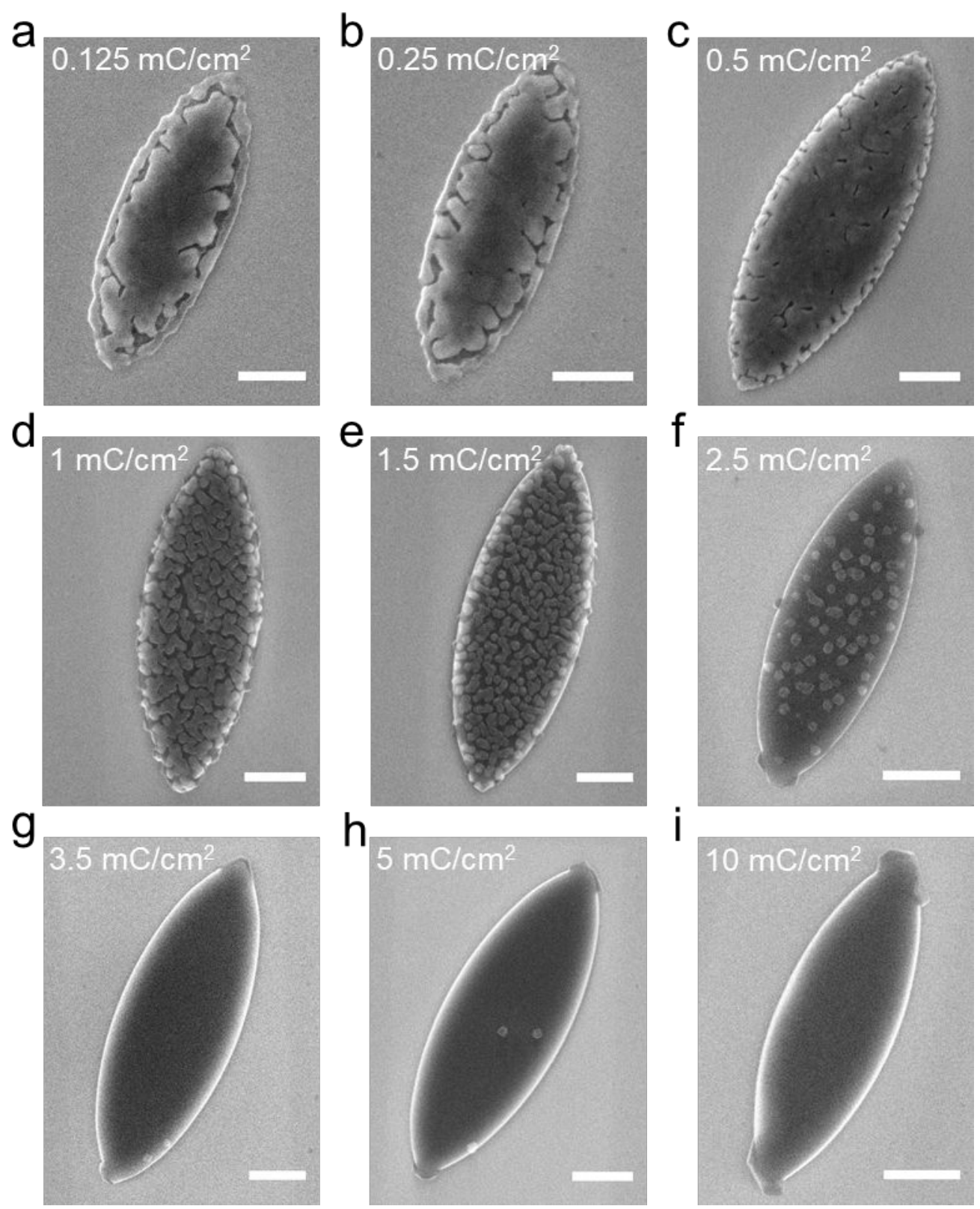

Figure S12. SEM images of ZIF-L particles (deposited on same Si wafer) after VPLT with 2$\mathrm{mIm}$ at $100{ }^{\circ} \mathrm{C}$ for 1 hour with prior e-beam exposure at $5 \mathrm{keV}$ and a dose of 0.125 (a), 0.25 (b), 0.5 (c), 1 (d), 1.5 (e), 2.5 (f), 3.5 (g), 5 (h) and 10 (i) $\mathrm{mC} / \mathrm{cm}^{2}$. Scale bars are $1 \mu \mathrm{m}$. It is noted that the onset of nucleation varies from wafer to wafer. 

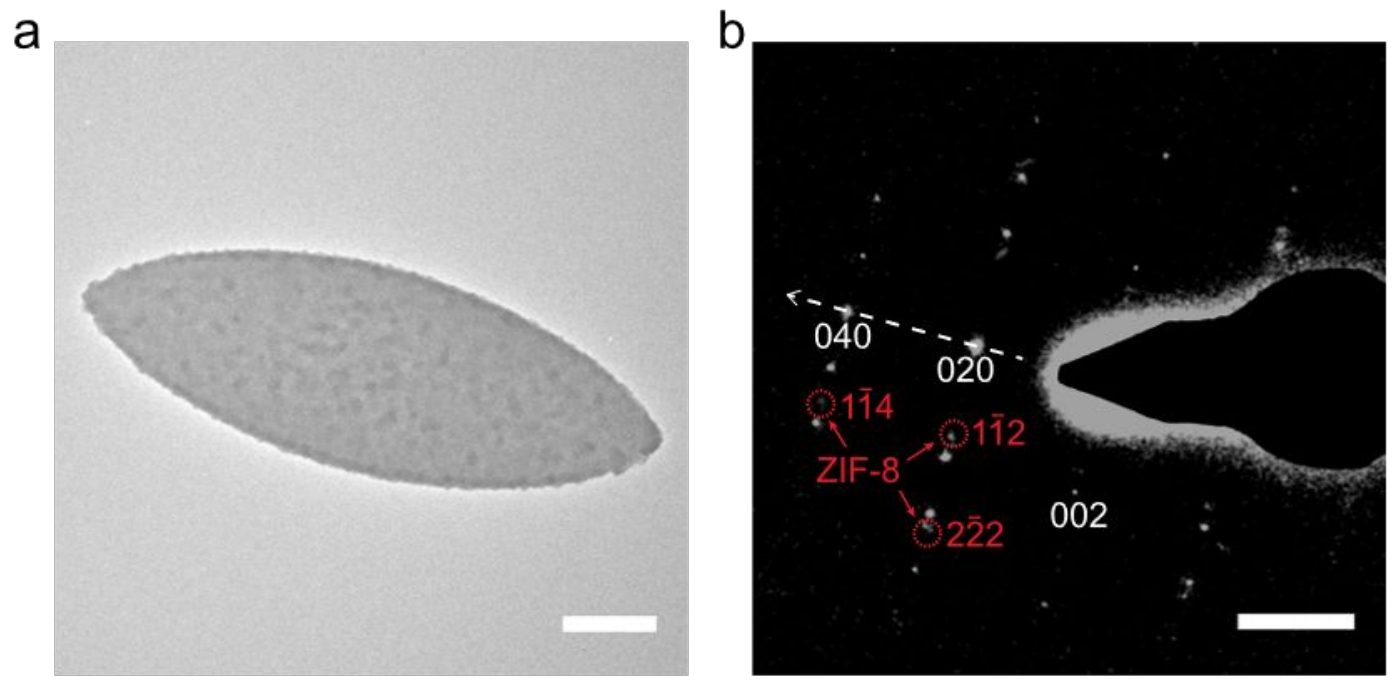

Figure S13. TEM image (a) of a ZIF-L particle after VPLT with 2-mIm at $100{ }^{\circ} \mathrm{C}$ for 1 hour with prior e-beam exposure at $5 \mathrm{keV}$ and $0.5 \mathrm{mC} / \mathrm{cm}^{2}$ dose, and corresponding diffraction pattern (b) with diffractions assigned to ZIF-L ([100] zone axis) and ZIF-8 ([110] zone axis) labelled in white and red, respectively. Arrow shows [010] direction of ZIF-L and [001] direction of ZIF-8. Scale bar is $1 \mu \mathrm{m}$ in (a) and $1 \mathrm{~nm}^{-1}$ in (b). 

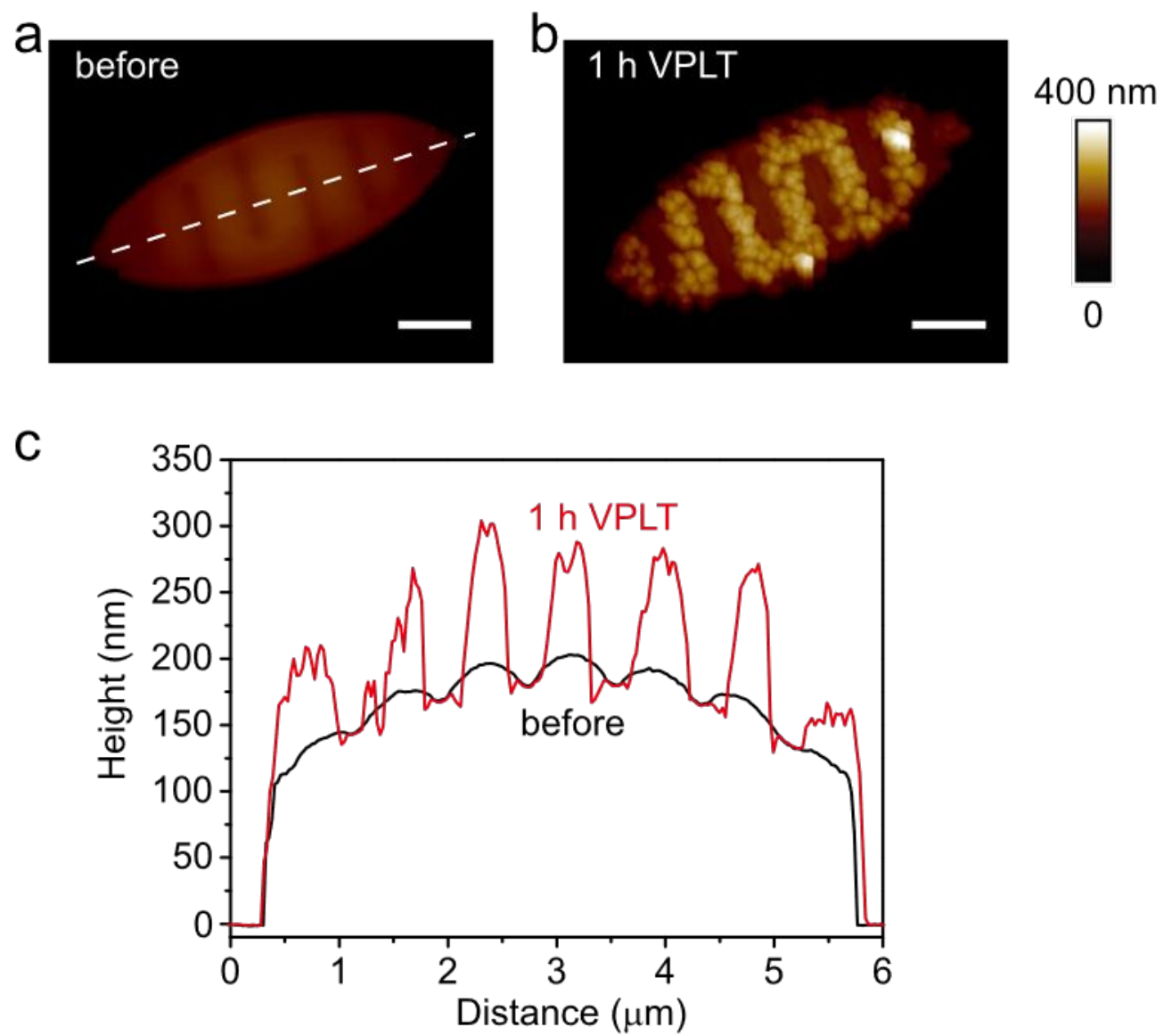

Figure S14. AFM image of a ZIF-L particle irradiated with a staggered strip pattern at $5 \mathrm{keV}$ and $10 \mathrm{mC} / \mathrm{cm}^{2}$ dose before (a) and after (b) VPLT crystallization for $1 \mathrm{~h}$ at $100^{\circ} \mathrm{C}$, and the AFM height profile measured across the long dimension of the particle (shown by the dashed line in a). Scale bars are $1 \mu \mathrm{m}$. 

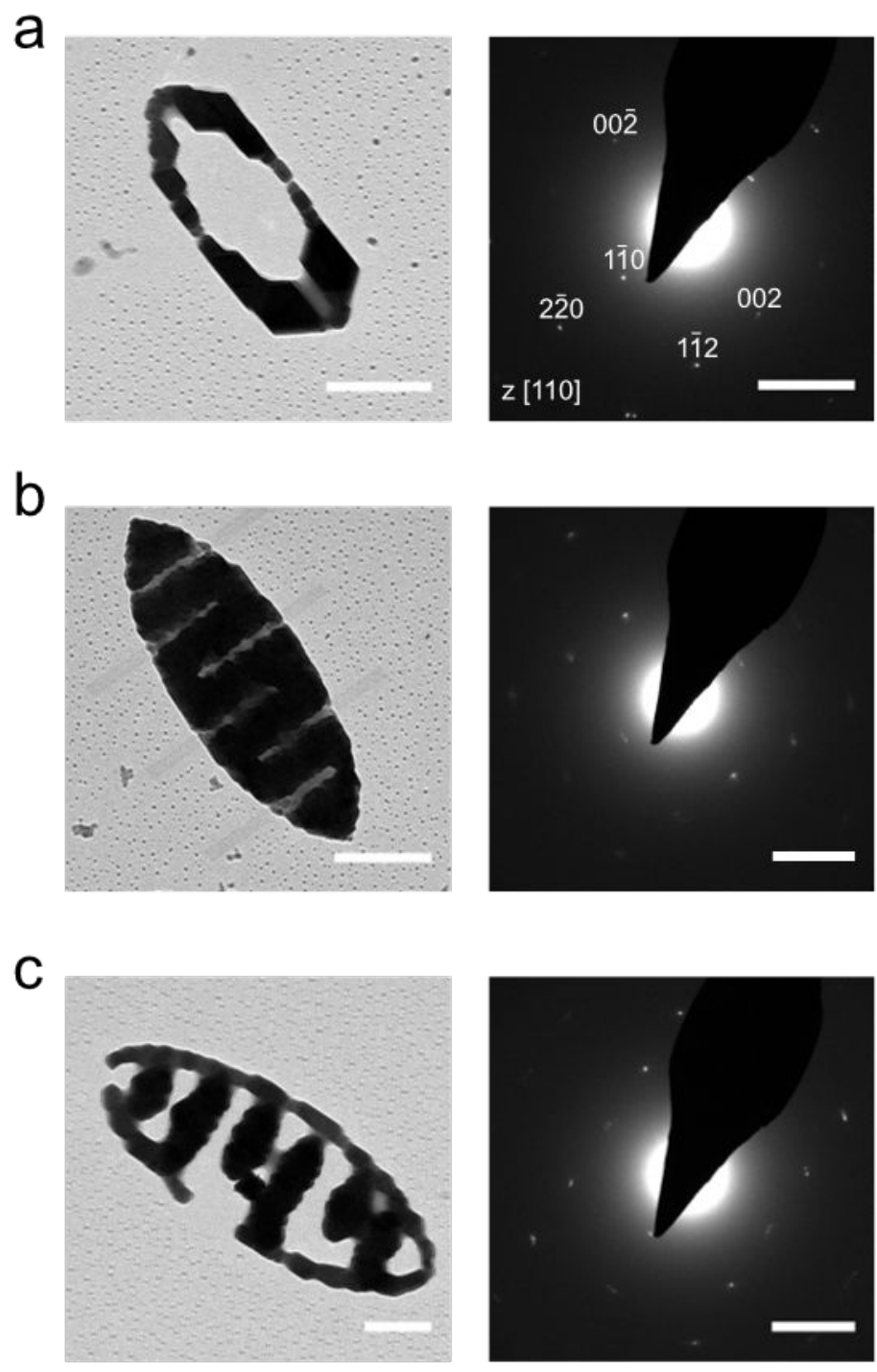

Figure S15. TEM image and ZIF-8 [110] zone axis ED pattern of ZIF-L particles after VPLT with $2-\mathrm{mIm}$ at $100{ }^{\circ} \mathrm{C}$ for $4 \mathrm{~h}$ with no prior e-beam exposure (a) and with high dose (b) and low dose (c) e-beam irradiation. Particles in (b) and (c) were irradiated with a stripe pattern at $5 \mathrm{keV}$ at $10 \mathrm{mC} / \mathrm{cm}^{2}$ and $0.5 \mathrm{mC} / \mathrm{cm}^{2}$ dose, respectively. ZIF-8 [110] zone axis diffractions are labelled in (a). Scale bars are $1 \mu \mathrm{m}$ in TEM images and $1 \mathrm{~nm}^{-1}$ in ED patterns.

\section{Reference}

1. Drouin, D.; Couture, A. R.; Joly, D.; Tastet, X.; Aimez, V.; Gauvin, R. Scanning 2007, 29 (3), 92-101. 